\title{
Simvastatin prevents proliferation and bone metastases of lung adenocarcinoma in vitro and in vivo
}

\author{
H. LIU, Z. WANG, Y. LI, W. LI, Y. CHEN* \\ Department of Orthopedic and Trauma Surgery, Qilu Hospital, Shandong University, Jinan 250012, China \\ *Correspondence: yunzhenchen2011@hotmail.com
}

Received July 5, 2012 / Accepted August 14, 2012

\begin{abstract}
Objectives: To explore the mechanism about how HMG-CoA reductase (HMGR) inhibitor inhibit proliferation and bone metastases of lung adenocarcinoma in vitro and in vivo.

Methods: The HMGR inhibitor simvastatin, human lung cancer cell line A549 and Balb/c nude mouse were used in this study. The mice were randomly divided into 2 groups: control group $(0.9 \% \mathrm{NaCl}$ solution, i.v.) and simvastatin group ( $5 \mathrm{mg} /$ kg simvastatin, i.v.). A scratch assay using A549 cell monolayer was also tested. An invasion assay using collagen-coated membrane in trans-wells was applied to evaluate the effect of simvastatin on the metastatic potential of A549 cells in vitro. The expressions of CD44, PUMA, P53, MMP2 and MMP9 were determined by real-time PCR and western blotting; the phosphorylation status of MAPK/ERK signaling parthway was investigated by western blot. .

Results: Compared with the control group, the migration of A549 cells in simvastatin-treated group was markedly inhibited $(\mathrm{p} \leq 0.01)$. Untreated A549 cells showed marked invasion, while simvastatin significantly inhibited the invasion of tumor cells ( $\mathrm{p} \leq 0.001$ ). Incubation of A549 cells with simvastatin significantly reduced the levels of CD44, MMP2 and MMP9 ( $<<0.01$ ), while significantly increased p53 ( $<<0.01)$. Simvastatin significantly inhibits tumor growth and bone metastasis in lung cancer xenograft mouse model, simvastatin can inhibit the kinase phosphorylation in MAPK/ERK signaling parthway.

Conclusions: The HMGR inhibitor simvastatin prevents proliferation and osteolytic bone metastases of lung adenocarcinoma cells in vitro and vivo. Its mechanism may be associated with regulation of CD44, P53, MMP family and inactivation of MAPK/ERK signaling parthway.
\end{abstract}

Key words: simvastatin, bone metastases, lung carcinoma, p53, CD44, MAPK/ERK

HMG-CoA reductase (HMGR) inhibitors are potent inhibitors of the 3-hydroxy-3-methylglutaryl coenzyme A reductase, the rate limiting enzyme in the mevalonate pathway for the biosynthesis of cholesterol [1]. These compounds have been used for decades as safe and effective drugs in the control of hypercholesterolemia. The mevalonate pathway produces also a number of important end-products, which include isoprenoid precursors, ubiquinone, dolichol and isopentenyladenine [2]. HMGR inhibitors also show anti-carcinogenic effects in rodent models of lung, prostate, melanoma, colon, glioma and mammary tumorigenesis, and beneficial effects of HMGR inhibitors have been seen in different cancers including lung cancer [3]. For example, a significant $20 \%$ reduction in overall cancer risk was observed in patients with HMGR inhibitor usage [4]. A recent study conducted in women, who used HMGR inhibitors, showed significantly reduced risk of breast cancer as compared to nonusers [5]. Moreover, an independent study reported a significantly lower risk of lung adenocarcinoma in a group who used HMGR inhibitors for more than 4 years [6].

Several distinct mechanisms have been proposed whereby HMGR inhibitors block tumor cell proliferation and induce apoptosis. For example, inhibition of geranylgeranyl pyrophosphate and farnesyl pyrophosphate production by HMGR inhibitors prevents the post-translational modification of Rho and Ras GTPases necessary for their membrane localization [2]. Rho proteins regulate the proliferative and invasive potential of various tumor cells including lung cancer cells, Thus suppression of geranylgeranylation of RhoA by HMGR inhibitors may significantly inhibit tumor cell growth. Additionally, by modulating the Ras GTPase function, HMGR inhibitors inhibit the MAPK cascade and CDK2 activity, which may affect the degradation of p21 and p27 cyclin kinase inhibitors that regulate cell proliferation and apoptosis [7]. 
Mortality in cancers, including lung cancer, is mainly dependent on the acquisition of metastatic phenotype of the cancer cells. Invasive power is controlled by many genetic and epigenetic changes that occur in the tumor cells. In fact, a dormant EMT (epithelial-mesenchymal trans-differentiation) program, sufficient to execute most of the steps of metastatic cascade, may be activated in a single step. The invasion-metastatic process is initiated by local invasion, called intravasation, followed by survival and translocation through the blood and lymphatic vessels leading to extravasation, formation of micrometastasis and finally colonization (macrometastasis) of the organ [8] .

The metastatic potential of tumor cells for different organs may be regulated by specific gene expression profiles inherent in the cancer cells as well as by the structure of the target organ. Thus lung adenocarcinoma metastasizes predominantly to liver, brain and bone. Previous study suggested MAPK/ERK signaling parthway plays an important role in the bone metastasis. In the present study, we show that simvastatin markedly prevents human A549 lung adenocarcinoma proliferation and metastasis to spine. Further, we examined the underlined mechanism fundamentally.

\section{Materials and methods}

Cell lines and reagents. A549 cells were obtained from ATCC (American Type Culture Collection). The cells were grown in DMEM supplemented with penicillin, streptomycin and $10 \%$ fetal bovine serum. Simvastatin was purchased from Novartis AG. CD44 antibody was purchased from Epitomics (USA); p53 antibody was obtained from Santa Cruz Inc. (USA); MMP2, MMP9, p-ERK, p-JNK, and p-raf-1 antibodies were obtained from cell signal Technology (USA); TriZol RNA isolation kit was purchased from Sigma-aldrich (USA). SYBR Green real time PCR master mix was obtained from SuperArray Biosciences (USA).

Bone metastasis examination in vivo. Immunocompromized $\mathrm{balb} / \mathrm{c}$ nude mice were purchased from the animal experimental center of medical school of Shan Dong University. All animal protocols were approved by the national Animal Care and Use Committee. Animals were housed in a specificpathogen-free facility with free access to food and water, under a constant temperature $\left(22 \pm 2{ }^{\circ} \mathrm{C}\right)$ and a daily illumination period of 12 hours (7:00 a.m. to 7:00 p.m.). Before inoculated by A549 cells, mice were injected with $10 \mathrm{mg} / \mathrm{kg}$ simvastatin every day for 7 days. Control mice received phosphate buffer saline. $1 \times 10^{7}$ A549 cells were inoculated into balb/c nude mouse by intravenous injection. After that, simvastatin was orally given for four weeks. At the end of four weeks, deeply anesthetized mice were X-rayed using a Faxitron radiographic inspection unit. The radiolucent areas of the hind limb on the X-ray plate were marked. The areas were quantified using a computer-assisted BIOQUANT image analysis program.

Human lung tumor xenografts. 12 female $\mathrm{Balb} / \mathrm{c}$ nude mice weighing 17-21g at 5-6 weeks of age were used for the anti-cancer efficacy study. The mice were randomly divided into 2 groups: (a) Control group $(\mathrm{n}=6)$ : xenograft tumors were developed, and treated with $0.9 \% \mathrm{NaCl}$ at $10 \mathrm{mg} / \mathrm{kg}$; (b) simvastatin-treated group $(\mathrm{n}=6)$ : xenograft tumors were developed, and treated with a dose of $10 \mathrm{mg} / \mathrm{kg}$ simvastatin; Then mice were housed in a laminar air-flow cabinet under specific pathogen-free conditions and provided food and water ad libitum, under a constant temperature $\left(22 \pm 2{ }^{\circ} \mathrm{C}\right)$ and illuminated 7:00 a.m. to 7:00 p.m.

To establish A549 xenografts in nude mice, animals were engrafted with $1 \times 10^{6}$ A549 cells (in $0.2 \mathrm{ml}$ of medium) s.c. in the right flank of each mouse using a 23-gauge needle. Once the tumors became palpable (mean size of $0.1 \mathrm{~mm}^{3}$ at day 12 after injection, mice were treated every day for 14 days with one of the following treatment schedules: $0.9 \% \mathrm{NaCl}, 10 \mathrm{mg} / \mathrm{kg}$ simvastatin. Tumor size was measured every three days using a caliper and tumor volume was calculated using the formula: $\mathrm{V}=\mathrm{a} \times \mathrm{b}^{2} / 2$, where $\mathrm{a}$ and $\mathrm{b}$ were respectively the largest and smallest perpendicular diameters. At day 14 after the treatment, the mice were sacrificed and the tumors were harvested for weight measurement. The inhibition rate of simvastatin on the tumor growth is calculated by the following formula:

$$
\text { Inhibition Rate }=\left[1-\frac{\text { Tumor Weight }(\text { treatment })}{\text { Tumor Weight }(\text { control })}\right] \times 100 \%
$$

Preparation of A549 cell lysate. A549 cells were incubated with simvastatin at $0.1 \mu \mathrm{M}$ and $1 \mu \mathrm{M}$ in vitro for 24 hours, after that, the cells were lysed in RIPA buffer $(20 \mathrm{mM}$ Tris-HC1, pH 7.5, $150 \mathrm{mM} \mathrm{NaCl}, 5 \mathrm{mM}$ EDTA, $1 \mathrm{mM}$ phenylmethylsulfonylfluoride, $0.05 \%$ aprotinin and $1 \%$ Nonidet P-40). The homogenates were centrifuged at $12,000 \mathrm{xg}$ at $4^{\circ} \mathrm{C}$ for 30 minutes. The cleared supernatant was used to determine the protein concentration using BioRad reagent.

Western blotting. Equal amounts of tumor or cell lysates were separated by SDS polyacrylamide gel electrophoresis. The separated proteins were electrotransferred to the PVDF membrane. The membrane containing the proteins was used for immunoblotting with required antibodies. The protein bands were scanned and quantified as a ratio to $\beta$-actin control, CD44, p53, MMP2 and MMP9 were tested in the current study.

RNA extraction and RT-PCR. Total RNA was prepared from A549 cells using Trizol RNA extraction kit. Total RNA was then reverse transcribed and qRT-PCR carried out using SYBR Green master mix and primers specific for CD44, p53, MMP2 and MMP9. The PCR amplification was performed in 7900 HT Sequence Detection System from Applied Biosystems. The amplification conditions are as follows. For CD44, MMP2 and MMP9: $94^{\circ} \mathrm{C}$ for 10 minutes followed by 40 cycles of $94^{\circ} \mathrm{C}$ for 30 seconds, $58^{\circ} \mathrm{C}$ for 30 seconds and $72^{\circ} \mathrm{C}$ for 30 seconds. For p53: $94^{\circ} \mathrm{C}$ for 10 minutes followed by 40 cycles of $94^{\circ} \mathrm{C}$ for 30 seconds, $55^{\circ} \mathrm{C}$ for 30 seconds and $72^{\circ} \mathrm{C}$ for 30 seconds. The PCR primers were listed following: CD44 primers: Forward: 5'-CCACGTGGAGAAAAATGGTC-3; Reverse: 


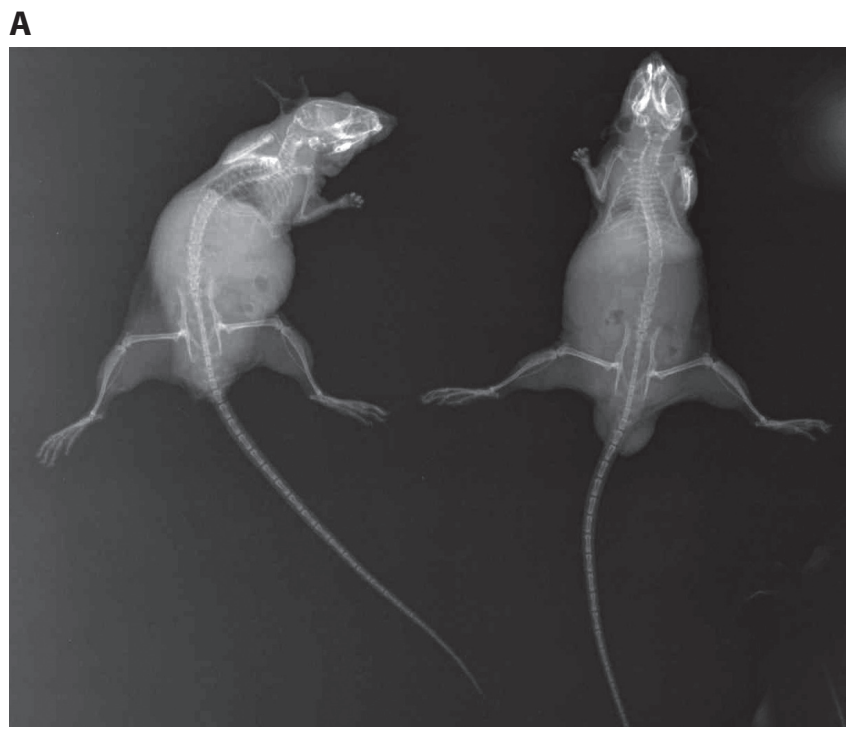

B

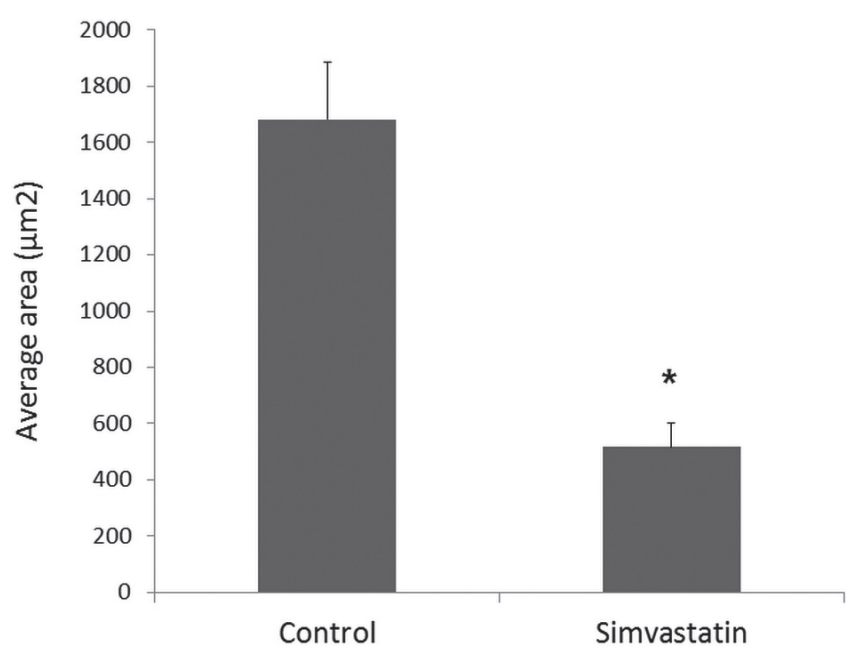

Figure 1. Simvastatin inhibited A549 metastasis to spine of nude mouse in vivo

Note: the left mouse received A549 i.v injection with saline treatment; right mouse received simvastatin treatment.

5'-CATTGGGCAGGTCTGTGAC-3; P53 primers: Forward: 5'-TGGTAATCTACTGGGACGGA-3'; Reverse: '-GCTTAGTGCTCCCTGGGGGC-3' ; MMP2 primers: forward: 5'
Forward Primer: 5'-GCCCCCATGAAGCCTTGT-3'; Reverse Primer: 5'-TTGTAGGAGGTGCCCTGGAA-3'; MMP9 primers forward, 5' -CCCCACTTACTTTGGAAACGC-3'; reverse, 5'-ACCCACGACGATACAGATGCTG-3'.

Statistical data. The significance of the data was determined using ANOVA followed by paired $t$ test or Student-NewmanKeuls analysis. The changes were considered significant if the $\mathrm{p}$ value was less than 0.05 .

\section{Results}

Simvastatin attenuates lung cancer cell metastasis to spine and proliferation in vivo. Saline or simvastatin-treated nude mice were injected with A549 cancer cells. As expected and shown in the X-rays, lung cancer cells metastasized to spine to produce significant osteolytic lesions in the spinal cords of nude mice (Figure 1A). However, in simvastatintreated group, bone lesions were markedly reduced (Figure 1A). Quantification of the osteolytic areas showed significant prevention of lung cancer metastasis to spine in the simvastatin-treated animals (Figure 1B). These results demonstrated that simvastatin prevented lung cancer metastasis to spine.

Simvastatin inhibits the A549 proliferation in vivo. The effects of the antitumor activity of simvastatin on tumor weight in the human lung cancer A549 xenograft model are shown in Table 1 and Fig 2 . At a dose of $10 \mathrm{mg} / \mathrm{kg}$, simvastatin showed significant anti-cancer effect $(p<0.01)$, inhibition rate is $69.01 \%$.

The effect of antituomr activity of simvastatin on tumor volume exhibits a strongly significant difference at a dose of $10 \mathrm{mg} / \mathrm{kg}$ with a value of 1.12 of RTV and $p<0.01$, (Table 2).

Simvastatin down-regulates CD44 both at protein and mRNA levels. To investigate the mechanism of HMGR-mediated inhibition of lung cancer cell invasion, we considered the involvement of CD44, as this cell surface antigen is enriched in epithelial tumor-initiating and metastatic cancer cells [9-11]. Furthermore, a role for CD44 in cancer metastasis has been established [12]. Incubation of A549 cells with simvastatin significantly reduced the levels of CD44 protein (Figure 3). Real time RT-PCR results revealed that simvastatin also significantly decreased the mRNA level of CD44 in a dosedependent manner (Figure 3).

Simvastatin regulates the expressions of p53, MMP2 and MMP9. As shown in Fig. 3, by both real-time PCR and western-blot, we found simvastatin could increase p53 expression

Table 1. Effect of anti-tumor activity of simvastatin on tumor weight

\begin{tabular}{|c|c|c|c|c|c|}
\hline \multirow[t]{2}{*}{ Group } & \multicolumn{2}{|c|}{$\begin{array}{c}\text { Body Weight } \\
(\text { mean + s.d, gram })\end{array}$} & \multirow{2}{*}{$\begin{array}{c}\text { Tumor Weight } \\
(\text { mean + s.d, gram })\end{array}$} & \multirow[t]{2}{*}{ Inhibition Rate } & \multirow[t]{2}{*}{$p$ value } \\
\hline & Pre-treatment & Post-treatment & & & \\
\hline Control (NS) & $20.1 \pm 0.6$ & $20.3 \pm 0.7$ & $0.36 \pm 0.07$ & & \\
\hline $\begin{array}{l}\text { Simvastatin } \\
(5 \mathrm{mg} / \mathrm{kg})\end{array}$ & $20.6 \pm 0.9$ & $15.8 \pm 0.8$ & $0.11 \pm 0.03$ & 69.01 & $<0.01$ \\
\hline
\end{tabular}


and meanwhile down-regulate MMP2 and MMP9, we hypothesized that was one of mechanisms by which simvastatin played an important role in anti-cancer therapy.

Simvastatin inhibits the phosphorylation status of kinase in MEKK/ERK. By analysis of western blot, we found simvastatin treatment did not show significant inhibiton effect on total protein levels of Raf, Akt, and Erk. However, simvastatin could block significantly the phosphorylation status for $\mathrm{p}$-Raf, p-Akt and p-Erk in a dose-dependent manner (Fig.4). Phosphorylation is important for keeping these kinase activities.

\section{Discussion}

The osteolytic nature of lung cancer metastasis to bone results from complex interaction between lung tumor cells and surrounding bone marrow stoma, which leads to bone destruction and intense pain. In the present study, we demonstrate a novel action of simvastatin in preventing the osteolysis resulting from human lung cancer cell metastasis. We showed that simvastatin inhibited both metastasis of A549 cell and proliferation in vivo. Our results provided evidence that simvastatin attenuated the expression of CD44, which regulates migration and invasion of lung cancer cells. We also show that simvastatin increases the levels of p53 in A549 cells to repress the expression of CD44, meanwhile, metastasis-related MMP2 and MMP9 were also down-regulated by simvastatin.

What induces the lung cancer cells to metastasize to distant sites in an organ-specific manner is not clear. However, emerging results shed light on lung-specific metastasis of human A549 lung cancer cells, indicating that expression of specific gene sets may be involved in this phenomenon. For example, epiregulin, MMP1 and Cox2 are expressed mainly in the solid lung tumor and promote angiogenesis. However, when they are manifested in the disseminated cancer cells in the circulation, they increase the extravasation of these cells into lung parenchyma $[13,14]$. Although a gene expression profile indicated involvement of fibroblast growth factor signaling for lung cancer relapse in bone, a tight association between primary solid tumor gene expression and bone metastasis has not been reported [15]. Many of these factors act on osteoclasts to induce production and secretion of RANKL (receptor activator of NFxB ligand) that promotes osteoclastogenesis and cause the formation of osteolytic lesions in bone. Our results demonstrate that the HMGR inhibitor simvastatin significantly
A

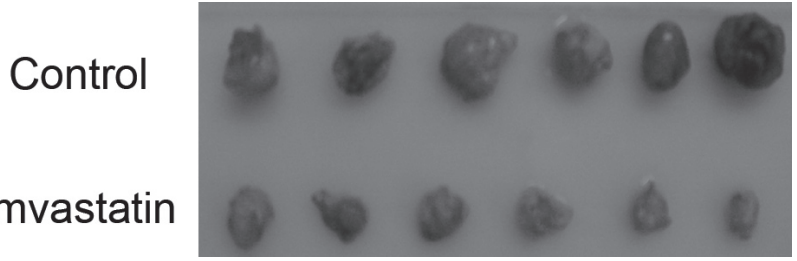

B

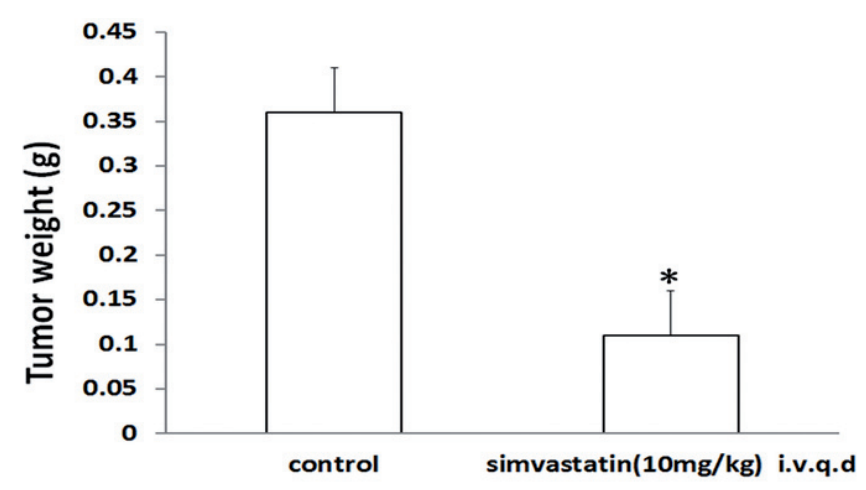

C

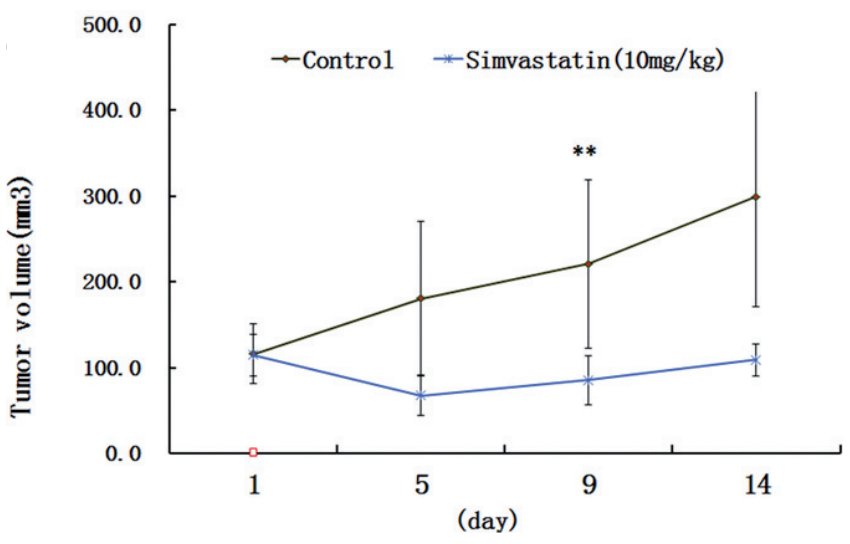

Figure 2. Simvastatin inhibited A549 proliferation in xenorgraft mouse model. A) Representative picture of tumors; B) Bar graph showed inhibition rate of simvastatin; C) Bar graph showed the change of tumor volume.

prevents the formation of osteolytic lesions caused by the metastasis of human A549 lung cancer cells to the bone (Fig. 1). This effect of simvastatin may result from its action on the

Table 2. Anti-tumor activity of simvastatin on tumor volume in nude mice

\begin{tabular}{|c|c|c|c|c|c|c|c|c|}
\hline \multirow[t]{2}{*}{ Group } & \multirow{2}{*}{$\begin{array}{c}\text { Dosage } \\
\text { (mg/kg x times) }\end{array}$} & \multicolumn{2}{|c|}{ Mice Number } & \multicolumn{2}{|c|}{$\begin{array}{c}\text { TV } \\
\left(\mathrm{mm}^{3}, \text { mean } \pm \text { s.d }\right)\end{array}$} & \multirow[t]{2}{*}{ RTV } & \multirow[t]{2}{*}{$\mathrm{T} / \mathrm{C}(\%)$} & \multirow{2}{*}{$\begin{array}{l}\text { p value } \\
\text { (t-test; tumor volume } \\
\text { compared to control) }\end{array}$} \\
\hline & & $\mathrm{D} 1$ & D14 & D1 & D14 & & & \\
\hline Control & & 6 & 6 & $116.08 \pm 35.17$ & $298.96 \pm 109.01$ & 2.58 & & \\
\hline simavastatin & $5 \times 14$ & 6 & 6 & $114.47 \pm 24.14$ & $128.29 \pm 18.50$ & 1.12 & 43.41 & $<0.01$ \\
\hline
\end{tabular}

Note: TV stands for tumor volume; RTV for relative tumor volume, which is the ratio between the tumor volumes at D14 and D1; T/C for treated group/ control group. 
A

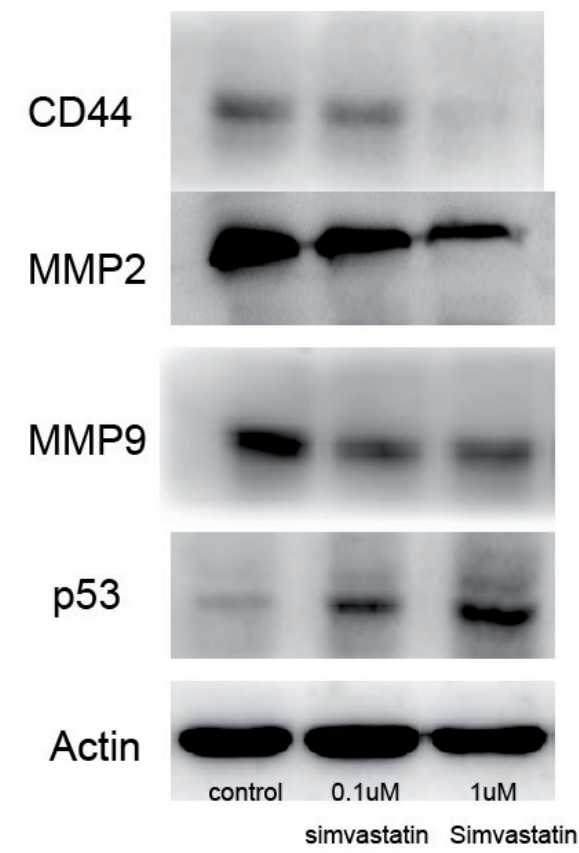

B

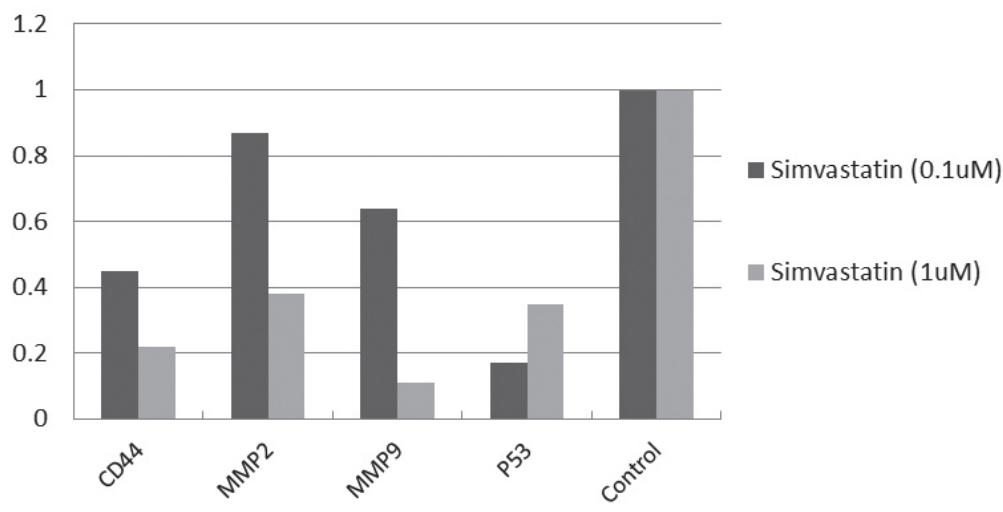

Figure 3. Simvastatin inhibited protein level of CD44, MMP2 and MMP9, while increased the p53 protein level.

Note: A: left lane: control; middle lane: $0.1 \mathrm{uM}$ simvastatin; right lane: $1 \mathrm{uM}$ simvastatin.

B: mRNA expression ratio by real-time PCR analysis for CD44, MMP2, MMP9 and p53. Compared to PBS-treated control, the mRNA expression ratio was calculated by simvastatin-treated expression was divided by control expression.

A

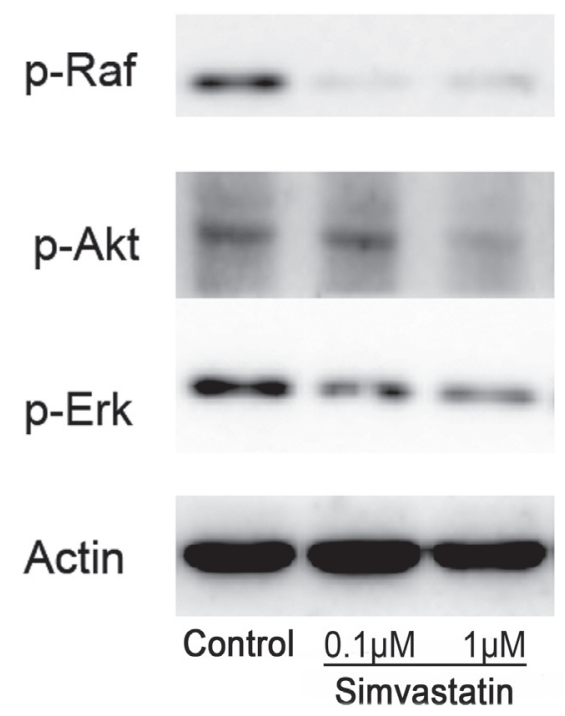

B
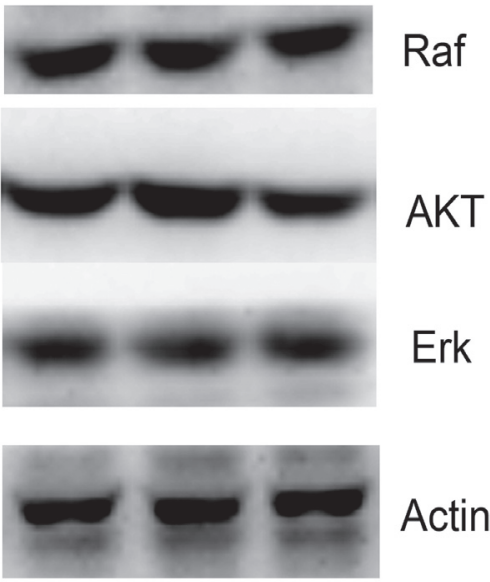

Actin

\section{Control $\underline{0.1 \mu \mathrm{M} \quad 1 \mu \mathrm{M}}$ \\ Simvastatin}

Figure 4. Simvastatin inhibited the phosphorylation status of Akt, ERK and Raf.

Note: A: Phosphorylated protein levels of Akt, ERK and Raf, B: Total protein levels of Akt, ERK and Raf. left lane: control; middle lane: $0.1 \mathrm{uM}$ simvastatin; right lane: 1uM simvastatin.

colonized lung cancer cells in bone to inhibit the production and secretion of the osteoclastogenic factors described above. These results indicate that HMGR inhibitors may attenuate the metastasis of lung cancer cells.
Rather absence of CD44 significantly prevented their dissemination to form micro- and macro-metastasis in lung and liver. In fact invasive property of the human lung cancer cells was tightly linked to the presence of CD44 [16]. In A549 lung cancer 
cells, which represent the mesenchymal phenotype, $85 \%$ of the population was positive for $\mathrm{CD} 44$, and show positive correlation with the "bone metastasis signature" protein expression [16]. Our results show that HMGR inhibitors suppress the expression of CD44 mRNA and protein in A549 cell. These results provide the evidence for a mechanism and for a salutary role of HMGR inhibitors in lung cancer metastasis.

CD44 represents the main receptor for hyaluronan, a nonsulfated disaccharide of D-glucuronic acid (1-(3-3) and $\mathrm{N}$-acetylglucosamine (1-(3-3), although CD44 binds to other extracellular matrix proteins including fibronectin, collagen and osteopontin, the extracellular domain adjacent to the transmembrane segment of CD44 contains a variable region due to inclusion of various combinations of exons 6-15 via differential splicing. Lung cancer cells express the smallest CD44s lacking the variable exons along with different variable isoforms (CD44v) [17]. Both CD44s and its various splice variants play an important role in lung cancer metastasis ${ }^{[17]}$. The cytoplasmic domain of all CD44 isoforms contains a 72 amino acid segment, which binds to ankyrin and ERM proteins [17]. Binding of hyaluronan or other extracellular matrix ligands to the extracellular domain increases its interaction with ezrin and ankyrin to modulate the cytoskeleton necessary for cell migration/invasion and metastasis. Also, the extracellular domain of CD44 acts as a coreceptor for various receptors tyrosine kinases such as EGFR and VEGFR by directly binding to the HB-EGF and VEGF.

Binding of hyaluronan to CD44 has been shown to be necessary for invasion and metastasis in mammary cancer. Hyaluronan has been detected in the endothelium lining of the bone marrow capillaries [18]. Thus, presence of CD44 on the A549 cells promotes extravasation into the bone marrow cavity. Apart from this, collagen I, being the main constituent of the bone matrix and a potent ligand for CD44, can contribute to the extravasation process of the lung cancer cells. In fact proteolytically active MMP9 is associated with CD44 on the surface of lung tumor cells. Therefore, MMP9-containing lung cancer cells recruited within the bone matrix may potentiate degradation of collagen I to increase bone resorption. Another important function of CD44-trapped MMP9 on the lung cancer cell surface is to produce mature TGF-3, which facilitates metastasis of lung cancer cells to bone [17]. Also, TGF-3 increases production of PTHrP by the tumor cells to induce osteoclastic activity in the bone microenvironment. Our observation that simvastatin blocks the expression of CD44 in the A549 cells in vitro and in the xenografts demonstrate that this HMGR inhibitor may prevent metastasis of lung cancer cells to the bone. This conclusion is also supported by the results showing significant prevention of the formation of osteolytic lesions in the simvastatin-treated animals (Figure 1).

P53 has been shown to suppress cancer cell invasiveness [19]. A recent report demonstrated that early premalignant mammary cells isolated from p53 null mice showed increased mammosphere formation, indicating that p53 suppresses mammary stem cell self-renewal mainly by suppressing the "symmetric self-renewing divisions" [20]. Lung cancer stem cells enriched for CD44 contribute to invasiveness, downregulation of this mutated p53 in A549 cells. Also, our results demonstrate that inhibition of p53 expression in these lung cancer cells significantly upregulated the expression of CD44 via a transcriptional mechanism. Together, our results provide evidence that p53 present in the A549 human lung cancer cells contribute to expression of CD44 necessary for migration and invasion of these cells.

Phosphorylation of MAPK/ERK signaling pathway plays big roles in origination, invasion and metastasis of lung cancer, in the current study, we confirm simvastatin could reduce their phosphorylation levels, then the this signaling pathway is blocked, and that is one of underlying mechanisms.

In summary, simvastatin is potential to be good medicine in clinical treatment for lung cancer, its thorough mechanism needs further study.

Acknowledgments: We appreciate China natural funding for support of this research project.

\section{References}

[1] WONG WW, DIMITROULAKOS J, MINDEN MD, PENN LZ. Hmg-coa reductase inhibitors and the malignant cell: The statin family of drugs as triggers of tumor-specific apoptosis. Leukemia 2002; 16: 508-519. http://dx.doi.org/10.1038/ sj.leu. 2402476

[2] DEMIERRE MF, HIGGINS PD, GRUBER SB, HAWK E, LIPPMAN SM. Statins and cancer prevention. Nat Rev Cancer 2005; 5: 930-942.

[3] ANDRADE SE, DONAHUE JG, CHAN KA, WATSON DJ, PLATT R. Liver function testing in patients on hmg-coa reductase inhibitors. Pharmacoepidemiol Drug Saf 2003; 12: 307-313. http://dx.doi.org/10.1002/pds.832

[4] GRAAF MR, RICHEL DJ, VAN NOORDEN CJ, GUCHELAAR HJ. Effects of statins and farnesyltransferase inhibitors on the development and progression of cancer. Cancer Treat Rev 2004; 30: 609-641.

[5] KHURANA V, BEJJANKI HR, CALDITO G, OWENS MW. Statins reduce the risk of lung cancer in humans: A large case-control study of us veterans. Chest 2007; 131: 1282-1288. http://dx.doi.org/10.1378/chest.06-0931

[6] SASSANO A, PLATANIAS LC. Statins in tumor suppression. Cancer Lett 2008;260:11-19. http://dx.doi.org/10.1016/ j.canlet.2007.11.036

[7] WU J, WONG WW, KHOSRAVI F, MINDEN MD, PENN LZ. Blocking the raf/mek/erk pathway sensitizes acute myelogenous leukemia cells to lovastatin-induced apoptosis. Cancer Res 2004; 64: 6461-6468. http://dx.doi.org/10.1158/00085472.CAN-04-0866

[8] WEINBERG RA. Twisted epithelial-mesenchymal transition blocks senescence. Nat Cell Biol 2008; 10: 1021-1023. http:// dx.doi.org/10.1038/ncb0908-1021 
[9 HANAI J, DORO N, SASAKI AT, KOBAYASHI S, CANTLEY LC et al. Inhibition of lung cancer growth: Atp citrate lyase knockdown and statin treatment leads to dual blockade of mitogen-activated protein kinase (mapk) and phosphatidylinositol-3-kinase (pi3k)/akt pathways. J Cell Physiol 2012; 227: 1709-1720. http://dx.doi.org/10.1002/ jcp. 22895

[10] GODAR S, INCE TA, BELL GW, FELDSER D, DONAHER JL et al. Growth-inhibitory and tumor- suppressive functions of p53 depend on its repression of cd44 expression. Cell 2008; 134: 62-73. http://dx.doi.org/10.1016/j.cell.2008.06.006

[11] OUHTIT A, ABD ELMAGEED ZY, ABDRABOH ME, LIOE TF, RAJ MH. In vivo evidence for the role of cd44s in promoting breast cancer metastasis to the liver. Am J Pathol 2007; 171: 2033-2039. http://dx.doi.org/10.2353/ajpath.2007.070535

[12] JOSHUA B, KAPLAN MJ, DOWECK I, PAI R, WEISSMAN IL, et al. Frequency of cells expressing cd44, a head and neck cancer stem cell marker: Correlation with tumor aggressiveness. Head Neck 2012; 34: 42-49. http://dx.doi. org/10.1002/hed.21699

[13] GUPTA GP, NGUYEN DX, CHIANG AC, BOS PD, KIM JY et al. Mediators of vascular remodelling co-opted for sequential steps in lung metastasis. Nature 2007; 446: 765-770. http:// dx.doi.org/10.1038/nature05760

[14] PADUA D, ZHANG XH, WANG Q, NADAL C, GERALD WL et al. Tgfbeta primes breast tumors for lung metastasis seeding through angiopoietin-like 4. Cell 2008; 133: 66-77. http://dx.doi.org/10.1016/j.cell.2008.01.046

[15] NGUYEN DX, BOS PD, MASSAGUE J. Metastasis: From dissemination to organ-specific colonization. Nat Rev Cancer 2009; 9: 274-284. http://dx.doi.org/10.1038/nrc2622

[16] SHERIDAN C, KISHIMOTO H, FUCHS RK, MEHROTRA S, BHAT-NAKSHATRI P et al. Cd44+/cd24- breast cancer cells exhibit enhanced invasive properties: An early step necessary for metastasis. Breast Cancer Res 2006; 8: R59. http://dx.doi. org/10.1186/bcr1610

[17] ORIAN-ROUSSEAU V. Cd44, a therapeutic target for metastasising tumours. Eur J Cancer 2010; 46: 1271-1277. http://dx.doi.org/10.1016/j.ejca.2010.02.024

[18] PASQUINELLI G, VINCI MC, GAMBERINI C, ORRICO C, FORONI L et al. Architectural organization and functional features of early endothelial progenitor cells cultured in a hyaluronan-based polymer scaffold. Tissue Eng Part A 2009; 15: 2751-2762. http://dx.doi.org/10.1089/ten.tea.2008.0232

[19] WANG SP, WANG WL, CHANG YL, WU CT, CHAO YC et al. $\mathrm{P} 53$ controls cancer cell invasion by inducing the $\mathrm{mdm} 2$ mediated degradation of slug. Nat Cell Biol 2009; 11: 694-704. http://dx.doi.org/10.1038/ncb1875

[20] CICALESE A, BONIZZI G, PASI CE, FARETTA M, RONZONI S et al. The tumor suppressor $\mathrm{p} 53$ regulates polarity of self-renewing divisions in mammary stem cells. Cell 2009; 138: 1083-1095. http://dx.doi.org/10.1016/j.cell.2009.06.048 